\title{
Artistic Responses to Gender-based Violence
}

\author{
Fabian Saptouw \\ University of Cape Town, Faculty of Humanities, Michaelis School of Fine Art
}

\author{
Sianne Alves \\ University of Cape Town, Office of the Deputy Vice Chancellor \\ Office for Inclusivity and Change
}

Received 31 October 2018 • Revised 25 December 2018 • Accepted 28 December 2018

\begin{abstract}
This article will present the findings of an ongoing project linked to the intersection of art, public space and social justice issues. The goal of this paper is to evaluate the teaching project by assessing the creative process of a group of 52 first year fine art students at the University of Cape Town. This paper will review the choices the students made when challenged to develop responses in the form of textual, visual and temporary public interventions to the subject of gender-based violence. The project has been running for 7 years, but this paper will primarily focus on one assignment linked to the topic of gender based violence in 2018.
\end{abstract}

Keywords: humanities, art, socially responsive projects, gender-based violence, public art.

\section{Introduction}

The article will review the creative process of a group of 52 first year fine art students at the University of Cape Town. This paper will examine the choices the students made when challenged to develop responses to the topic of gender-based violence in the form of textual, visual and temporary public artistic interventions. The primary focus of this text will be the written work submitted by the students, although reference will be made to the overall collaborative art project.

The project was initially developed by Lucina Reddy, Sianne Alves and Fabian Saptouw as part of a strategy to create intersections between social justice issues and the fine art curriculum in 2012. The goal was to develop a project that enabled students to tackle socially relevant issues in a way that is meaningful for them on an academic and a personal level. The link between the concepts taught in the classroom and the increase in students' capacity to engage complex topics was important to the teaching team. The project has been running for seven consecutive years and featured in conferences, journal articles and the UCT paper ${ }^{1}$.

1 The last article is accessible at https://www.news.uct.ac.za/article/-2018-10-22-spotlight-on-genderbased-violence.

(C) Authors. Terms and conditions of Creative Commons Attribution 4.0 International (CC BY 4.0) apply. Correspondence: Fabian Saptouw, University of Cape Town, Faculty of Humanities, Michaelis School of Fine Art, 31-37 Orange Str., Gardens, Cape Town, 80oo, SOUTH AFRICA. E-mail: f.saptouw@uct.ac.za. 
As the years progressed various changes were made to the structure of the project and the contributions made by the students. One of the changes is the submissions that form the primary focus of this paper. The data analysed in this paper are the individual responses to a specific assignment related to gender-based violence.

- Socially responsive art projects encourage students to creatively engage complex social justice issues.

- Students are encouraged to engage in self-reflexive practices and discuss their conclusions with their peers and lecturers.

- Allowing students a space to articulate their perception of the topic and challenging them to analyze those perceptions are crucial to the learning process.

- The project grants students the opportunity to apply lessons from the class room in their written submissions.

This paper will provide information about the assignment, the evaluation process and the project's value as a teaching tool. A detailed discussion of the actual content of the student submissions will be detailed in the discussion section, as well as an indication of the overall results of the process. Through these points an argument will be made regarding the value of the project and what we can glean from student submissions.

One of the primary goals in this paper is to emphasize the value of students engaging the topics by virtue of the rationale they are presenting for their submissions. This positions students as active participants in the learning process, and enables them to express individual views as well as work collaboratively with their peers. This dual process is presented as a strength embedded in this teaching model for the intersection of art and social responsiveness.

\section{Method}

The project was assigned to a group of first year students in the BA Fine Art degree at the Michaelis School of Fine Art, University of Cape Town. There were 59 students in the class, and 52 students submitted the assignment. The reasons 7 students did not submit assignment included deregistering from the course, applying for a leave of absence and not meeting the deadline.

The assignment forms part of the coursework for Fine Art Foundation Course (Fin1005W). This compulsory course is only open to students registered for the BA(FA) and emphasizes critical thinking and visual literacy. The course provides training to facilitate the students capacity enter the realm of cultural production. A wide range of issues in relation to representation and display is tackled throughout the year. The course is taught over 24 weeks and includes lectures, readings, tutorials written assignments and gallery visits. The combination of these five elements provide students with a broad understanding of contemporary art, and grant them the opportunity to gain more knowledge about artistic practices in the South African context. Students submit multiple assignments which challenge them to examine the links between the lecture content and readings discussed in tutorials. The assignments counts for $70 \%$ of the final mark and a written exam counts for $30 \%$ of the mark.

This particular project is part of a set of three assignments linked to the topic of gender-based violence.

Each part of the assignment focuses on slightly different areas and is linked to the development of different core competencies. Listed below are the three assignments presented to the students. 


\section{Foundation Course - Week 13 Michaelis - OIC Collaborative Art project HIV/AIDS and Gender-based Violence Project}

Readings:

Bennett and Banyard (2016). Do friends really help friends? The effect of relational factors and perceived severity on bystander perception of sexual violence.

World Health Organization (2013). 16 Ideas for addressing violence against women in the context of the HIV epidemic: A programming tool.

Jewkes et al. (2007). Evaluation of Stepping Stones: A gender transformative HIV prevention intervention. Retrieved 16 August 2016, from

www.mrc.ac.za/policybriefs/steppingstones.pdf.

\section{Week 13 - PROJECT 1}

Working in groups make a proposal for two possible installation/interventions on UCT upper campus (or off campus if more appropriate for your concept) in response to the ideas discussed in the lecture and readings. EACH project must include either a public intervention or a performative element that requires viewer participation. This general group project description should be copied and pasted into all group members' red books. Research one of the following artworks and adapt it to make it relevant for a contemporary South African audience:

- LiseBjørneLinnert, Desconocida, Unknown, (2006 - ONGOING)

- Linda Stupart, WANTED (1999-2008), (2008)

- ThulileGamedze, On Cat-Calling in Cape Town (2013)

- Elsie Chiwa, Comfort Doll (2017)

- Amnesty International Sweden Campaign, Rose Petals (2009)

- Yoko Inoue, Untitled (2007)

- Kiki Smith, Rapture (2002)

- Yoko Ono, Cut Piece (1964-5)

- Belinda Blignaut - 8345223Jhb Biennale (1995)

- Kara Walker - The Battle of Atlanta... The End of Uncle Tom (1995)

- Clitoria, Claimyourspace (2017)

Keep the following points in mind when planning your intervention.

- Each group will be assigned one specific material for their project via lucky draw

- Any additional materials will have to be purchased by individual group members

- The aims of Office for lnclusivity and Change (OIC) - The OIC provides institutional responses to transformation, sexual and gender-based violence, disability and cultural change. Some of the operational areas of the office include facilitating cultural shifts (staff-student engagement or staff-staff engagement), disability support services, prevention programmes, education, sexual assault, harassment and discrimination.

- How the artwork relates to the UCT community.

- How the differences between your installation and the original artwork changes the meaning/value of the work.

- You are responsible for providing high quality photographic images of each project. Appoint a specific group member to take responsibility for this part of the project and We transfer ALL your images to Fabian.

- Please note that a photographer will be assigned to document the project, but we appreciate the class providing additional images when possible. 
F. Saptouw \& S. Alves - Artistic Responses to Gender-based Violence

You must use the following template for your project descriptions:

\begin{tabular}{|c|c|}
\hline \multicolumn{2}{|c|}{$\begin{array}{l}\text { Michaelis School of Fine Art and OIC Collaborative Art project } \\
\text { FIN1oo5W - Foundation Course \&FIN10o8W Foundations Of Visual } \\
\text { Literacy }\end{array}$} \\
\hline Original Art work: & \\
\hline Group members: & \\
\hline $\begin{array}{l}\text { Group contact } \\
\text { person- Cell \& } \\
\text { email }\end{array}$ & \\
\hline Concept 1: & \\
\hline Concept 2: & \\
\hline Project Materials: & \\
\hline $\begin{array}{l}\text { Additional Group } \\
\text { Materials: }\end{array}$ & \\
\hline $\begin{array}{l}\text { Any specific } \\
\text { exhibition } \\
\text { requirements: }\end{array}$ & \\
\hline
\end{tabular}

(1) Each group must email Fabian (f.saptouw@uct.ac.za) and Sianne Alves (sianne.alves@uct.ac.za) your proposals by MONDAY 31 JULY by 12:00. Please arrange amongst yourselves who will take responsibility for this task. We encourage everyone to consider that is a collaborative process and be open to discussing alternative methods to manifest the ideas you are proposing. Quite often the first proposal is very didactic and confrontation and changes need to be made after the proposal. We need to have your projects approved by UCT's Properties and Services before we can install them on Upper campus.

(2) Do a personal analysis of your group project. Argue for the link between the projects and the above stated requirements.

\section{Please note:}

The class has been divided into 8 groups. Your group will not be your mentor groups anymore

Use your tutorial to discuss the artwork you intend to re-invent and the site you will be installing in, as well logistics relating to your project. 
Foundation Course - Week 13

Michaelis- OIC Collaborative Art project

HIV/AIDS and Gender-based Violence Project

\section{Week 13 - PROJECT 2}

\begin{tabular}{l} 
(3) Select one object and one image that you feel represents gender-based violence. Scan \\
or photograph the objects at a high resolution (minimum $300 \mathrm{Dpi}$ - A4 size). Ideally we need \\
to be able to print these images as an A3 or larger. Remember to include a brief \\
motivation for your choices. A box will be placed in the lecture theatre and \\
outside Fabian's office (Room 3.o7, top floor, Old Medical School Building) \\
closer to the deadline for you to donate your object, please ensure that you label \\
your object with an identification tag. \\
When you make your selection, please ensure that you do not choose an image closely \\
associated with any existing awareness campaigns. Try to avoid explicit or graphic images \\
that merely illustrate the issue or reinforce existing stereotypes and problematic \\
representations of gender. Try to select images that relate to your perspective on the issue \\
and its prevalence in the contemporary moment. \\
(50-150 words) \\
Please note that the objects may not be returned to you depending on wear/tear and \\
exhibition presentation. If its an object that has a high level of personal value consider \\
submitting a substitute. \\
\hline Answer one object: \\
Answer - Motivation: \\
Answer one image: \\
\hline Answer - Motivation: \\
(4) Select a colour that you feel represents your relationship to gender based violence. Ensure \\
that you provide the name, a colour sample and a brief motivation for your choice. \\
(50 words) \\
\hline
\end{tabular}

DEADLINE - Monday 6 August

The three outcomes of this assignment are the following submissions:

- Project 1-Part A - A temporary public intervention produced in collaboration with their peers.

- Project 1 - Part B - A personal reflection of the group work project allowing each student to voice their opinions about the nature of public art and social responsiveness.

- Project 2 - Students select a colour, an object and an image that represents genderbased violence and draft a text that provides a motivation for their selection.

These responses to the brief are submitted after an extended process of engagement with the staff members teaching the project. The first step in this process is a lecture that sensitizes students to gender-based violence and how it is represented in the popular media, academic texts and artistic production. During the lecture various examples of awareness campaigns are discussed as well as a critique of the manner these campaigns communicate with the audience. 
One of the primary issues emphasised during the lecture is the fact that didactic poster-driven campaigns often alienate the viewer and close down opportunities for discussion instead of creating safe spaces for engagement. Creating a platform for public engagement through art is the primary motivation for retaining this project as part of the fine art curriculum since 2012. It is a vital part of the curriculum that challenges students to think about the role that art can play in public discourse. This alerts students to the value of producing art for consumption outside of the traditional gallery space, and develops their capacity to create communicative gestures that engage socially relevant issues.

Specific art-historical references are discussed that engage the issue and allow the audience a space of empathy and participation. This strategy creates avenues for exploring these issues through communication and understanding and not by reinforcing binary dynamics related to problematic stereotypes and misrepresentations.

Listed below are the deadlines linked to the development of this project:

Project 1 - Deadlines

First proposals VIA EMAIL: Monday - 3o July by 12:00

- f.saptouw@uct.ac.za and sianne.alves@uct.ac.za

Feedback sessions: Wednesday - 1 August by 12:00-14:00

- More details to follow (Check VULA and First year notice board)

Finalized proposals: Wednesday - 22 August by 13:0o

- f.saptouw@uct.ac.za and sianne.alves@uct.ac.za

MATERIAL HANDOVER - Wednesday - 5 September in Foundation

Lecture

Installation week: Week of 18-22 September - Wednesday 19 September -

Installation event

Final Write up (Red Book work) Monday - 1 October

\section{Project 2 - Deadline - Monday 6 August by 12:00}

Based on the deadlines listed above it should be clear that students have the opportunity to consult their lecturers and tutors for a 6-7 week period to develop the public intervention for Project 1 . The materials assigned to the project groups included toothpicks, paper plates, wax wrap, cling film, sticky notes, A4 paper and clear tape. These mundane items were selected because they could be easily found in many homes and have very clear functions to fulfill in a domestic space. Another motivation was to shift the students' attention away from traditional art mediums and encourage them to be aware of the material possibilities that surround them during their everyday routines.

The submission of Project 2, the main focus of this paper, is a week after their first proposals and feedback sessions take place. During these sessions each group engages in conversations with their lecturers to review their project proposals. This provides students with ample time to revise the initial proposal to accommodate any critique received from the teaching staff. These conversations, related to the intersection of art, public space and gender-based violence are also intended to make students more aware of the value of socially responsive art. Based on these elements students should have the relevant knowledge base and confidence in their own capacity to provide more individual responses to the issues as outlined in Assignments Project 1 - Part B (self-reflexive evaluation) and Project 2 - Colour, object and image analysis.

Students submit the assignments in hard copy and online using VULA. This web portal is used for the dissemination of all course related information like assignments, course outlines, readings, lectures and course evaluations. It is also used to communicate with the entire class by sending announcements directly to their official UCT student email address. Each course has its 
own VULA site and is accessible to all the students, administrators, lecturers and tutors involved in the course.

It is important to note that all three assignments are evaluated by the tutors and the course convenor as part of an academic course at the institution, and that the marks are presented to an external examiner at the end of each academic year. The marks for these assignments count proportionally more than the other individual course assignments submitted by the students during the rest of the year.

\section{Results}

Students have to consider the capacity of artistic practice to provide an access point for viewer engagement with the topic of gender-based violence. This is done with all three submissions, but each requires slightly different strategies of articulation. In the context of this particular assignment the following three primary themes have become apparent during the review process.

The first is the notion of the body as the primary site for discourse related to genderbased violence. There was a very clear articulation of how disempowering certain social narratives are regarding the body. Ideas related to authority, power and claiming a position on how one is perceived was an important sub-theme in the submissions. This was both in relation to the body as a potential site of trauma and the body as a vehicle through which we can process that trauma and experience a healing process.

The second point was an engagement with the notion of home, as a constructed space linked to myriad cultural narratives. Many of these narratives featured a critique of the power dynamics within domestic spaces, as well as an interrogation of the images published in the popular media. Students reflected on their own development up to this point in their lives as a crucial marker for how they were encouraged to accept socially constructed ideas. Depending on the individual's background, this was also a fertile space for interrogating previously held assumptions and beliefs.

The last theme was the importance of the context and perspective we, as viewers and participants, bring to a situation, especially when it requires individualised responses. Overall, the class was very sensitive to the ambiguity of certain objects, images and statements that could be used both to heal and to harm. The submissions reflected a keen awareness of their own subjectivity, but also a concerted effort to critique the social bias that is evident in heteronormative ideas regarding gender, violence and identity.

The overall goal of the project was not to identify how this group of students define gender-based violence through objects and colours, but to gain a clearer understanding of the students' ability to synthesise complex data presented in the classroom and use it as a foundation for articulating their own ideas. In this project we see evidence that the students have the capacity to engage extremely difficult subject matter by using the aforementioned items as intermediaries to represent their analytical process. Through this process the students shifted from being passive consumers of information in the classroom and became active participants in the learning process. This shift is crucial in allowing the students to actively engage the learning process and gain a clearer understanding of the subject matter through that critical engagement.

Not only were the participants able to negotiate the complex social issues but they presented the ability to empathise with the pain of others. In a few cases the assignment was a trigger for specific individual experiences; attempting to accommodate this by the way the questions are phrased is something that will be included in future manifestations of the project. Finding ways to engage such a deeply personal trauma was challenging to these students, but the 
responses indicated an extremely high level of self-awareness and careful consideration of how to engage that trauma in the context of an assignment at a tertiary academic institution.

\section{Discussion}

\subsection{Discussion - Object selection}

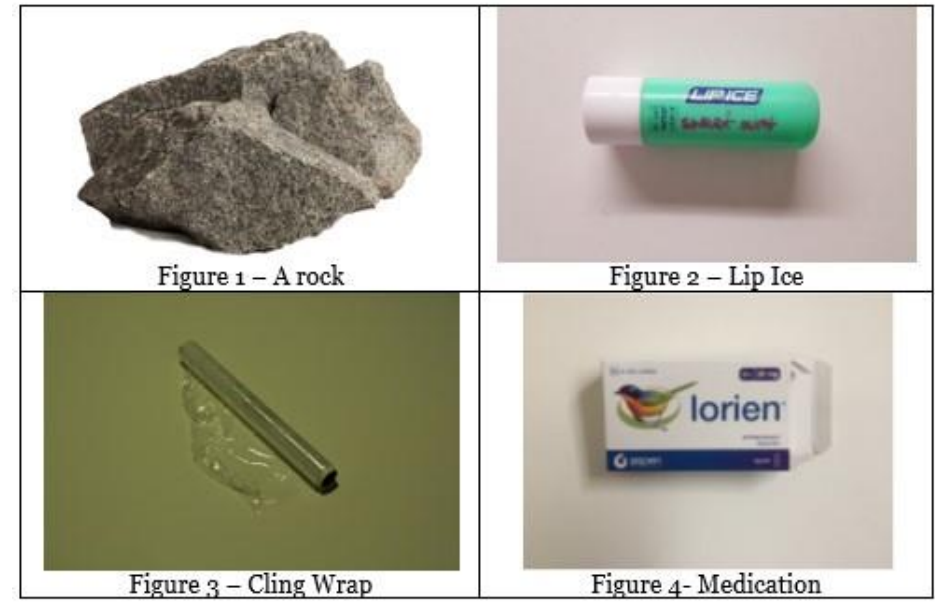

The majority of the class, $60 \%$, elected to work with items that were related to the human body. These items could be worn, applied, ingested or used for a predetermined function. $25 \%$ of these body-related objects were specifically designed for the female body with student selections made in the areas of hygiene, beauty and medicine. These items included: sanitary pads, cosmetic products, razors, oral contraceptives and deodorant. There were also body-related items which could be used by both male and females; like Lip Ice, belts, gloves and aprons. These objects transformed or augmented the body - by masking it, protecting it, covering blemishes or removing unwanted items from it. Often these transformations were required to complete a task, prepare for an event, or conform to socially reinforced ideals of beauty.

$12 \%$ of these objects were domestic items like porcelain plates, pegs, batteries, tea bags and gloves - these objects were broadly linked to the notion of 'home' by the students. The motivation behind the object choices presented a very gendered interpretation of the domestic space and were often linked to positive and negative childhood experiences. The text accompanying the selection of these objects indicated a turning point in the candidate's perception of the past events and a re-evaluation of previously held beliefs.

$12 \%$ of the class submitted items that were broken or damaged. These examples ranged from a cup that was damaged by accident, a toy that was discarded by a child to a glass that was smashed intentionally by an angry parent. In all cases there was an issue around the value of the items being subject to the passage of time, and in rare cases - malicious intent. When one considers these as a group of linked gestures, you could postulate that this particular selection of objects are a representation of the vulnerability of the body, especially given the poignant manner in which the students articulated their concerns.

$12 \%$ of the objects were linked to the category of access or protection; these included locks, keys, nets and other barriers that restrict entry into an area. In the narration of their concerns the students expressed an awareness of how an item like a lock can be used to keep an area secure, to lock your valuables away or to imprison someone. This awareness of the ambiguity of these objects was an interesting set of observations. This interpretive position was also extended to items that we may be more comfortable with - like cling wrap, a broom, masks and even paper 
planes. In each of these cases the students were able to draw out specific associations that made the objects an important symbol in their personal narrative.

On a personal level, I found these narratives particularly effective when the candidates reflected on both the predetermined functional value of the object as well as their personal associations. The ability to support the dual reading of the object in such a short text was very impressive. Quite a few students discussed how their own understanding of the world and the construction of gendered boundaries have affected their choices in life. There were 6\% of submissions that explicitly stated this as a self-analysis, but in actuality it is embedded in virtually all the projects submitted by the class.

Only $15 \%$ of the objects were directly linked to violence; examples included physical abuse, intimate partner violence, female genital mutilation and child abuse. $8 \%$ of submissions related to the abuse of alcohol and drugs, which echoed some of the problematic visual language of the awareness campaigns mentioned earlier. These explicit examples are an indication that some members of the class felt strongly that explicit images and objects remain central in conveying the message. This selection was slightly problematic given the time invested in prompting the students to develop a broader understanding of the topic and how to visualize this information.

One submission that was very memorable was bubble wrap crafted from sanitary pads, in this instance the student crafted an item that clearly embodied the intention of the project. The object is not only linked to the function of the bubble wrap as a protective barrier in the real world, but also links it to the complex issue of representation of the gendered body. By merging the issue of protection, value and menstruation the student created a point of discussion that was a very effective way to claim a public space for an often ignored issue.

There was also one candidate who approached their cousins with a request to contribute toys as part of their submission for the project. The tenderness of the moment of approaching someone much younger to discuss such a difficult topic stood out as a very valuable humane moment of consideration. These kinds of encounters echo the primary reason for originally developing the project, because there is great importance attached to the attempt to create spaces of dialogue around complex social issues.

In this case more than the ensuing two sections the students were focusing on their personal associations with the objects and trying to narrate the way these mundane items that surround us have been transformed by virtue of the knowledge they have gained through this project. In this case ubiquitous items like a wooden peg, a Bic lighter and yellow rubber gloves are imbued with significance far beyond their material value, and starts to metaphorically link with issues of power, politics, gender and identity.

\subsection{Discussion - Image selection}

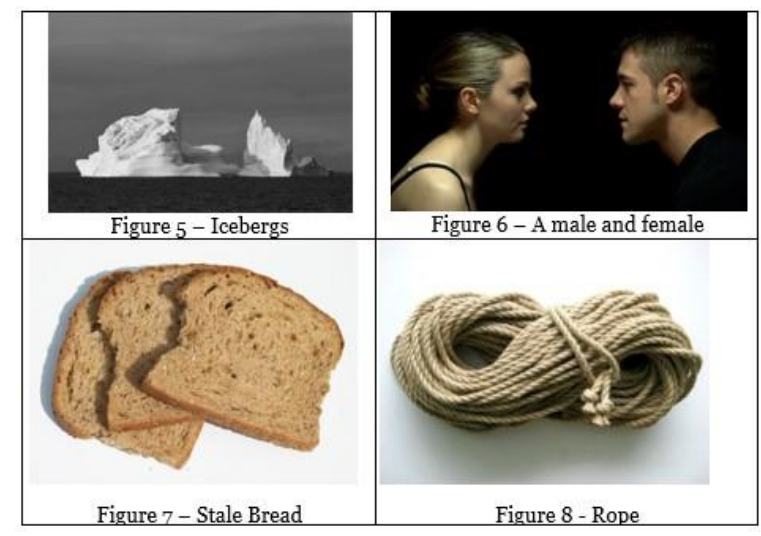


$50 \%$ of the class submitted images that included people and the rest elected to focus on objects or environments. What is clear is that the students generally link the topic of genderbased violence to the human body - present physically, presented as evidence of trauma or implied by traces in the landscape. There was a split in the submissions between students trying to provide evidence of the issues and being aware of the ability of the image to transcend that immediate set of references.

$27 \%$ of the class selected images that were either linked to awareness campaigns or confronted the viewer with examples or traces of gender-based violence. These included bruised bodies, injuries and images that represented child abuse. These submissions relied on established symbols and associations that were already circulating in the popular imagination. The one example that was included in this grouping but moved beyond it, was an information graphic advocating the use of colour correcting make-up. This was paired with a design similar to a lifestyle magazine and indicated how to choose your cosmetic colours based on the bruising you wish to conceal and how the colour combinations needed to change based on the time since the initial injury.

$17 \%$ were images taken in a domestic space, $25 \%$ were not in a built environment and the rest of the images did not provide enough contextual information to clearly situate it. Based on the comments provided by the students, there seems to be the sentiment that this could happen in nearly any environment.

There was a group of students who elected to focus on artists and artworks as their chosen image. The artists selected for this portion of the project were quite fascinating because they work in very different media and subject matter. The list of artists included Man Ray, Pablo Picasso, Jenny Saville, Luxloop, John Everett Millais, Edvard Munch, Christina Migliorini, Pippa Moolman and Heitor Magno. Out of the $25 \%$ of artworks submitted in the image category only 6\% were produced by female artists. It is interesting to note that the students did not select any of the artists that were discussed in the lectures or readings, but instead sought their own set of references.

The choice of artworks as their image, particularly the Picasso or the Munch, has a clear art-historical sense of value. The inclusion of artworks that have become canonical in various art history courses within this grouping is a creative way to reinvent the link between the canon and the subtle messages embedded in these artworks.

Only $5 \%$ of the class selected images that utilised abstraction as a primary visual language. This was regarded as a missed opportunity given the breadth of associations with abstract art as an established trajectory in artistic production. Given the nuance of the answers presented in the colour assignment in the next section, I anticipated more reference to the symbolism of colour and how that can act as an interpretive framework for experiencing the world. This was not something the students capitalized on in their responses to the project.

The majority of the responses related to the notion of gender-based violence on a somatic level. This shifted between a generalized account of the issues which attempted to be inclusive of all parties and more personal accounts narrating their motivation for selecting specific images. Overall, there was a concerted effort to generate empathetic responses to the topic and opening spaces of consideration for all parties involved. 


\subsection{Discussion - Colour selection}

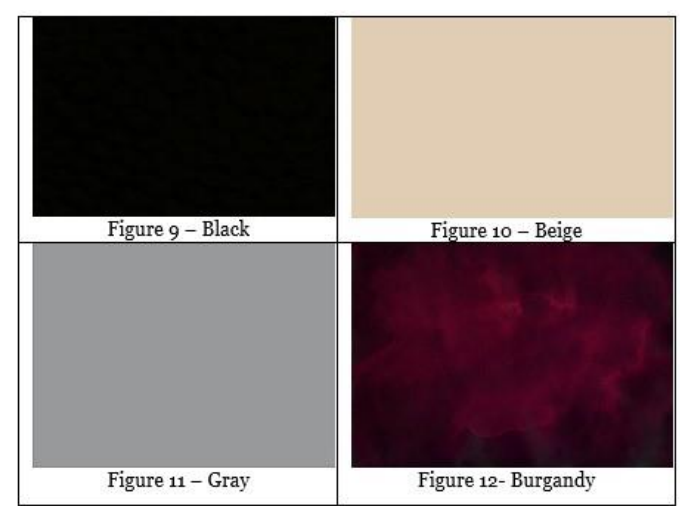

It is important to note that the evaluation of the colour choice project is complicated by the subjectivity linked to individual colour preferences as well as the contradictory cultural associations of specific colours. In addition it is important to note that the value of the answer is not based on the pre-defined meaning of these colours, but rather how the students were able to link colours to the topic of gender-based violence. The most popular colours were red (21\%), black (13\%) and purple (19\%). The rest of the colours include orange, silver, teal, gray, green, pink, beige, brown, yellow and blue. $27 \%$ of the class chose primary colours, $44 \%$ secondary colours, $4 \%$ tertiary colours and the remaining students all selected white, black and gray.

The motivations for the selection of the colours were as important to the assessment exercise as the colours themselves. For example, the selection of red was often related to blood, passion, violence, injuries and other intense emotional experiences. The text that accompanied these selections linked to established representations in the popular media and existing literature. Based on that information the majority of the red submissions could be regarded as quite generic associations and possibly reflected too much of a reliance on pre-existing associations. Only a few of this group of submissions provided inventive links by presenting red as the colour of resistance, empowerment and in one case even linking it with The Total Shutdown: Intersectional Women's March Against Gender-Based Violence held in South Africa.

Motivation for the selection of black included the representation of the colour as a void, or darkness which could cloud human experiences after an incident of trauma. It is important to acknowledge that the majority of these associations were negative and often included words like horror, depression, oppression, trauma, hurt, pain, evil and death. These examples were quite literal in its framing of gender-based violence and the impact it had on survivors. In addition, the students also referred to the absence of light, and other colours as an indication of an emotive state.

The first set of associations for the colour purple was also unfortunately linked to the colour as evidence of domestic violence and injury. This selection was slightly problematic given the time invested in prompting the students to develop a broader understanding of the topic and how to visualize this information. This focus on bruises and the body could have been developed significantly further given the input provided. This was however a subsection of the motivation for students selecting purple as the colour representing the issue of gender-based violence.

A more nuanced motivation was provided by the students who regarded purple as important because of the fact that is a secondary colour created by mixing the primary colours blue and red. Or, as students often presented it - the pink and blue associated with heteronormative ascriptions of gendered identity during childhood. This choice indicates an awareness of the way biological sex, gender and sexuality are often conflated on a social level. In 
addition it highlights the fact that both men and women are afflicted by the scourge of genderbased violence, a fact that is often not discussed openly in society.

An interesting phenomenon was the handful of students who didn't select colours primarily on their association with some kind of trauma, but rather through the evocation or the impressions of the colour. One candidate specifically selected a 'sickly teal' to represent the inability they felt in expressing their distaste at the way women are often treated by men in public spaces. In this case the student was not discussing the meaning of the colour, but rather connecting the colour with a visceral sensation in response to the issue.

Another student selected Shamrock green as a gender-neutral colour-space which was regarded to be more welcoming to non-binary gendered individuals. Light panzer was another choice that stood out due to the candidate's ability to argue for the occurrence of rust as an environmental hazard linked to the interaction of materials. The potential of rust occurring through the oxidization of metal was linked to the frequency of gender-based violence in the world.

There were also candidates who elected to engage their own experiences, and found ways to negotiate their past by selecting colours because of the way it framed their sense of self. These selections were extremely powerful as they not only spoke to the privacy of the experience but also about the immense difficulty of coming to terms with the trauma.

The majority of the class didn't rely on the established meanings often attributed to the range of colours selected. The submissions reflect an earnest attempt to develop individual definitions of the issue by careful examination of the interpretive link between the colour and its ascribed meaning. Developing this level of individual response to the issue of representation is a crucial component of their training as cultural producers in the contemporary moment.

\section{Conclusion}

Through these assignments we can see that students in this group have a clear understanding of gender-based violence. Their success in this regard should be celebrated due to the challenging nature of the creation of visual and linguistic responses to an issue of such magnitude. In each section there is evidence that the students engaged in careful deliberations of the complexity of the issue. Choosing a colour, an image and an object challenges each student to critically re-evaluate their associations and lived experiences to try and find an appropriate response to the prompt. The challenge not to duplicate the trauma or reinforce negative mainstream messaging requires that students have to find creative ways of approaching the issue of representation.

This is also the point at which we can see how the lessons in the class room translates into their ability to source information, commit to a specific symbolic gesture and draft a supporting document for their project. Overall, the students found inventive ways to refer to the experience of gender-based violence. Students who presented the most nuanced assignment were the candidates who have engaged the three topics in an inter-connected manner that allows for a more complex symbolic register to develop.

There is a marked difference in the range of associations drawn in this project, and the way the students worked with the materials in the temporary public artistic intervention. In the group work project there is much more collaboration, whereas in this project students are challenged to develop an individual response. There is great value in understanding these submissions as a database to gain a broader understanding of how students related to the subject matter. At a first year level this is one of the few situations in which students are engaging socially responsive art projects, and it is an import skill to develop in each cohort of new recruits. It is also 
a useful project to keep monitoring in future to see how the students are making connections and developing interpretive frameworks to analyse complex social problems.

The value of the project is the fact that it is an effective way to measure student engagement and can be adapted to suit various topics or control groups. The core of the project is to challenge participants to develop responses linked to their primary research interest or field of expertise. Variations of this project can be easily developed to accommodate cognate disciplines or even be applied in a workshop format in its current formulation. The primary goal was to create spaces for the development of dialogues centred on complex subjects like the intersection of art, public space and social justice issues.

\section{Acknowledgements}

This research did not receive any specific grant from funding agencies in the public commercial, or not-for-profit sectors.

The authors declare no competing interests.

\section{References}

Bennett, S., \& Banyard, V. L. (2016). Do friends really help friends? The effect of relational factors and perceived severity on bystander perception of sexual violence. Psychology of Violence, 6(1), 6472. http://dx.doi.org/10.1037/a0037708

Jewkes, R., Nduna, M., Levin, J., Jama, N., Dunkle, K., Wood, K., Koss, M., Puren, A., \& Duvvury, N. (2007). Evaluation of Stepping Stones: A gender transformative HIV prevention intervention. Retrieved 16 August 2016, from www.mrc.ac.za/policybriefs/steppingstones.pdf.

World Health Organization (2013). 16 ideas for addressing violence against women in the context of the HIV epidemic: A programming tool. WHO Document Production Services, Geneva, Switzerland. Retrieved 16 August 2016, from http://apps.who.int/iris/bitstream/10665/95156/1/9789241506533_eng.pdf. 
F. Saptouw \& S. Alves - Artistic Responses to Gender-based Violence

C O A $\mathbf{s}$ 